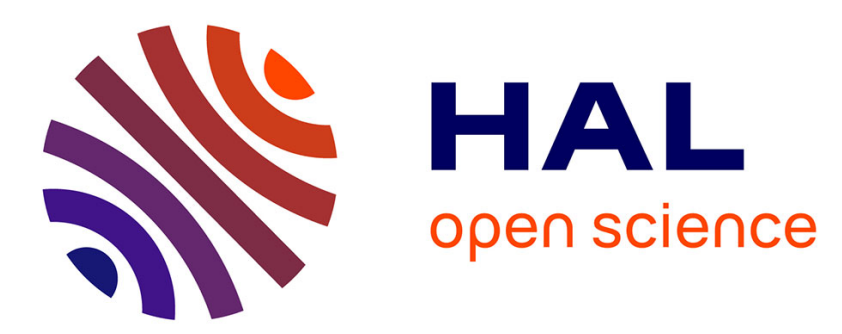

\title{
Unexpected behavior of InSb alloy for Mg-Ion batteries: unlocking the reversibility of $\mathrm{Sb}$
}

\author{
Lucie Blondeau, Eddy Foy, Hicham Khodja, Magali Gauthier
}

\section{To cite this version:}

Lucie Blondeau, Eddy Foy, Hicham Khodja, Magali Gauthier. Unexpected behavior of InSb alloy for Mg-Ion batteries: unlocking the reversibility of Sb. Journal of Physical Chemistry C, 2018, 123, pp.1120-1126. 10.1021/acs.jpcc.8b10913 . cea-01965738

\section{HAL Id: cea-01965738 https://hal-cea.archives-ouvertes.fr/cea-01965738}

Submitted on 27 Dec 2018

HAL is a multi-disciplinary open access archive for the deposit and dissemination of scientific research documents, whether they are published or not. The documents may come from teaching and research institutions in France or abroad, or from public or private research centers.
L'archive ouverte pluridisciplinaire HAL, est destinée au dépôt et à la diffusion de documents scientifiques de niveau recherche, publiés ou non, émanant des établissements d'enseignement et de recherche français ou étrangers, des laboratoires publics ou privés. 


\title{
Unexpected Behavior of InSb Alloy for Mg-ion
}

\section{Batteries: Unlocking the Reversibility of Sb}

\author{
Lucie Blondeau, ${ }^{1 *}$ Eddy Foy, ${ }^{2}$ Hicham Khodja, ${ }^{1}$ Magali Gauthier ${ }^{1 *}$ \\ ${ }^{1}$ LEEL, NIMBE, CEA, CNRS, Université Paris-Saclay, CEA Saclay, 91191 Gif sur Yvette \\ Cedex, France \\ ${ }^{2}$ LAPA-IRAMAT, NIMBE, CEA, CNRS, Université Paris-Saclay, CEA Saclay, 91191 Gif sur \\ Yvette Cedex, France
}

*Corresponding authors: magali.gauthier@cea.fr +33 1690845 30; lucie.blondeau@cea.fr +33

169086496 


\section{ABSTRACT}

Electrochemical behavior and performance of negative electrodes in metal batteries can be modified and improved by combining different elements. Herein, a beneficial coupling of In and $\mathrm{Sb}$ in the alloying reaction with $\mathrm{Mg}$ was considered through the preparation of the InSb alloy by mechanochemical synthesis. Despite a strong inactivity of $\mathrm{Sb}$ as a sole element in $\mathrm{Mg}$-ion batteries, the combination of $\mathrm{Sb}$ with In partially unlocks the reversibility of the alloying reaction of $\mathrm{Sb}$ with $\mathrm{Mg}$ to form $\mathrm{Mg}_{3} \mathrm{Sb}_{2}$. For the first time, this beneficial effect is not only observed during the first magnesiation but along few tens of cycles. The analysis of the behavior of $\mathrm{InSb}$ through electrochemical and X-ray diffraction measurements also revealed a more complex path than reported in the literature. Uncommonly a preferential electrochemically-driven amorphization of MgIn is suggested in standard galvanostatic measurements. Crystallization of MgIn is however observed through a galvanostatic intermittent titration technique, suggesting strong kinetic effects on the microstructure, strain or disorder in the InSb phase upon magnesiation. 


\section{Introduction}

The Li-ion batteries production might face some sustainability issues in a near future due to the relatively low abundance and uneven concentration of lithium on the Earth crust and more importantly due to the cobalt criticality. Magnesium $(\mathrm{Mg})$-based batteries are a promising alternative thanks to $\mathrm{Mg}$ high abundance, low price, safety features and its attractive theoretical capacities $\left(2200 \mathrm{mAh} \mathrm{g}^{-1}\right.$ and $\left.3800 \mathrm{mAh} \mathrm{cm}^{-3}\right) \cdot{ }^{1-4}$ Alike lithium, magnesium metal has a tendency to react with conventional electrolytes. However magnesium transport is limited by the formation of a blocking passivation layer on its surface instead of an ions conducting solidelectrolyte interphase (SEI) for lithium. ${ }^{1,2,4-7}$ This layer impedes the $\mathrm{Mg}^{2+}$ ions path to the $\mathrm{Mg}$ negative electrode, and thus dramatically limits the reversible stripping/plating electrochemical processes. Aurbach's ${ }^{6-8}$ group, among others, has overcome this problem in the 2000 s, using Grignard reagents in an organohaluminate-based electrolyte in ethereal solution. Unfortunately, the difficult preparation conditions, their extreme air-sensitive and corrosive characters as well as their instability, limit their use in industry. ${ }^{2,4,9,10}$ Above all, the narrow electrochemical window of organohaluminate-based electrolytes makes it difficult to develop high-voltage positive electrode materials. ${ }^{6,8}$ An interesting alternative for the development of magnesium batteries is to replace magnesium metal with a negative electrode material, which should be compatible with conventional electrolytes. Such Mg-ion cells could be a reliable alternative to lithium-based systems. Recently, some studies showed that $p$-block elements $\left(\mathrm{Sn},{ }^{11-17} \mathrm{Sb},{ }^{18,19} \mathrm{In},{ }^{17,20,21} \mathrm{~Pb},{ }^{22}\right.$ $\mathrm{Bi}^{5,18,23-27 \ldots)}$ can electrochemically alloy with $\mathrm{Mg}$ and can be stable with conventional electrolyte such as $\mathrm{Mg}(\mathrm{TFSI})_{2}$ dissolved in a glyme solvent. ${ }^{5,26}$ Despite their interesting electrochemical reactivity, these alloys present lower theoretical gravimetric capacities than $\mathrm{Mg}$

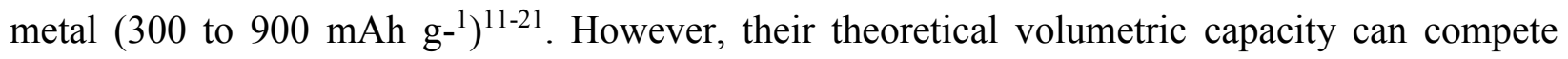
with $\mathrm{Li}$ or $\mathrm{Mg}$ metal, with for example a value of $\sim 1900 \mathrm{mAh} \mathrm{cm}^{-3}$ for bismuth. Among these 
elements, indium presents the lowest alloying potential $\left(0.09 \mathrm{~V}_{\mathrm{Mg}}\right)$ and a good reversibility but suffers from kinetics limitations at high rates and scarce resources. ${ }^{17,20}$ Differently, antimony presents one of the highest theoretical capacity $\left(660 \mathrm{mAh} \mathrm{g}^{-1}\right),{ }^{18,19}$ despite its lack of electrochemical activity as pure element. Magnesiation of pure $\mathrm{Sb}$ to form $\mathrm{Mg}_{3} \mathrm{Sb}_{2}$ was only observed in thin films, ${ }^{19}$ while poor- if any- alloying occurs for pure micrometric Sb particles. ${ }^{18}$ In any case, Sb electrodes present a strong irreversibility and capacity fading. ${ }^{18,19}$

$\mathrm{Bi}_{1-\mathrm{x}} \mathrm{Sb}_{\mathrm{x}}$ and $\mathrm{SnSb}$ alloys were respectively investigated by Murgia et al. ${ }^{18}$ and Parent et al. ${ }^{11}$ as negative electrodes for Mg-ion batteries to seek for a synergy between the different elements. The first authors evidenced that antimony can be activated when coupled with bismuth. However, this beneficial effect is only observed on the first magnesiation as $\mathrm{Mg}^{2+}$ ions cannot be pulled out of the $\mathrm{Mg}_{3} \mathrm{Sb}_{2}$ structure in the subsequent demagnesiation. ${ }^{18}$ Differently, Parent et al. ${ }^{11}$ revealed that the electrochemical reaction with $\mathrm{Mg}$ modifies $\mathrm{SnSb}$ particles into a network of $\mathrm{Sn}$ and $\mathrm{Sb}$ subparticles, where only $\mathrm{Sn}$ remains electroactive. The presence of $\mathrm{Sb}$, inactive towards $\mathrm{Mg}$, enhances the performance of Sn through the formation of an interface stabilizing Sn into its cubic phase. A beneficial coupling of In and Bi in the InBi alloy was also explored by Murgia et al. ${ }^{21}$ No clear synergy exists in InBi but a complex conversion-type electrochemical mechanism with multiple intermediate phases was evidenced..$^{21}$

In this work, a synergy between In and $\mathrm{Sb}$ in the InSb alloy was investigated by electrochemical analysis and ex situ X-Ray Diffraction (XRD). In a new way, Sb is shown to reversibly react in part with $\mathrm{Mg}$. An electrochemically-driven amorphization $^{28}$ is here demonstrated for the first time for MgIn in Mg-ion batteries, by analogy with other alloys such as silicon in $\mathrm{Li}$-ion batteries ${ }^{28}$ or $\mathrm{SnSb}$ in Na-ion batteries. ${ }^{29}$ 


\section{Methods}

In (Alpha Aesar, 99.99\%) and Sb (Alpha Aesar, 99.5\%) powders were purchased and used as received. The InSb compound was prepared by planetary ball milling in a Fritsch Pulverisette with 3 stainless steel balls in a stainless-steel vial. In and Sb powders were introduced in stoichiometric amount with a ball-to-powder ratio of 1:70 and milled for $6 \mathrm{~h}$ under inert atmosphere (Ar). A milling yield (corresponding to the ratio of powder masses after and before milling) higher than 95\% was obtained, demonstrating poor welding between the powder and the balls/vial.

Powders samples were characterized by XRD on a RU-200B rotating anode X-ray generator using monochromotized Mo radiation $(\lambda=0.7093 \AA)$. Scanning Electron Microscopy (SEM) was performed on a SEM-FEG Zeiss Ultra 55 model operating at $3 \mathrm{kV}$ in order to study the morphology of the InSb powder.

Composite electrodes were formulated by mixing 80 wt.\% of the InSb ball-milled active material with 10 wt.\% of carbon (Csp, 99+ \%, Alfa Aesar) and 10 wt.\% of polyvinylidene fluoride (PVDF, Solvay Solef) with N-methyl-2-pyrrolidone (NMP, 99 \%, Acros Organics) as the solvent. The slurry was stirred for $30 \mathrm{~min}$ before being cast onto a $\mathrm{Cu}$ foil $(99.8 \%$, Alfa Aesar). The film was dried at room temperature during $24 \mathrm{~h}$ and subsequently for $24 \mathrm{~h}$ at $120^{\circ} \mathrm{C}$ under vacuum. Electrode disks were cut out and stored in a glove box. The average active material loading was around $0.35-0.52 \mathrm{mg} . \mathrm{cm}^{-2}$.

Electrochemical tests were performed in a half-cell configuration using 2-electrodes Swageloktype cells with a $\mathrm{Mg}$ disc $(99.95 \%$, Gallium Source) as both reference and negative electrode. Whatman GF/A glass microfiber filters were used as separators. The electrolyte consists of a mixture of ethylmagnesium chloride (EtMgCl, $2.0 \mathrm{M}$ in THF, Sigma-Aldrich) and 
diethylaluminium chloride ( $\mathrm{Et}_{2} \mathrm{AlCl}, 97 \%$, Sigma-Aldrich) in a 1:1 molar ratio solubilized in anhydrous tetrahydrofuran (THF, $99.9 \%$, Carlo-Erba). The final concentration of the organohaluminate complex "EtMgCl-Et $2 \mathrm{AlCl}$ " is estimated $\sim 0.35 \mathrm{~mol} . \mathrm{L}^{-1}$. All the operations of cell assembly were made in an Ar-filled glove box. Galvanostatic tests were performed at room temperature using a research-grade potentiostat (VMP3, Biologic) between 0.005 and $0.8 \mathrm{~V}_{\mathrm{Mg}}$ (vs. $\mathrm{Mg}^{2+} / \mathrm{Mg}$ ). The electrochemical tests were performed at $\mathrm{C} / 50$, if not otherwise mentioned, where $C / n$ rate means that the full magnesiation is reached in $n$ hours. $\mathrm{C} / 50$ rate corresponds here to a current density of $11 \mathrm{~mA} \mathrm{~g}^{-1}$. A galvanostatic intermittent titrate technique (GITT), which consists of a series of current pulses ( $\mathrm{CCV}$ : constant current voltage), each followed by a relaxation time (OCV : open-circuit voltage), was used to study the electrochemical mechanisms. In our case pulse periods of $1 \mathrm{~h}$ at a $\mathrm{C} / 50$ rate followed by open circuit courant (OCV) periods for $2 \mathrm{~h}$ were used. Every electrochemical test was repeated at least three times to verify the reproducibility.

Ex situ XRD characterization after cycling was performed on electrodes previously washed with THF to avoid any trace of the electrolyte. To avoid reactivity with air, all XRD measurements were carried out by protecting the sample with Kapton tape in the glove box.

\section{Results and discussion}

High energy mechanochemical synthesis is known as an efficient method to synthesize intermetallic compounds ${ }^{18,21,30-32}$ such as $\mathrm{InSb}^{33}$ The XRD pattern (Figure 1) and the profile matching (Supplementary Information, Figure S1) collected on the synthesized powder shows the formation of a cubic phase corresponding to the InSb compound with crystallographic parameters in agreement with the literature (space group $\mathrm{F} \overline{4} 3 \mathrm{~m}, \mathrm{a}=6.476 \AA \pm 0.003^{34}$ ). A small 
diffraction reflex at $18^{\circ}$ is also detected and is explained by iron impurities from the vial and balls during the milling process. The SEM image (Figure 1b) evidences the formation of large micrometric aggregates of around 1 to $10 \mu \mathrm{m}$ made of sub-micrometric particles roughly welded together.

a)

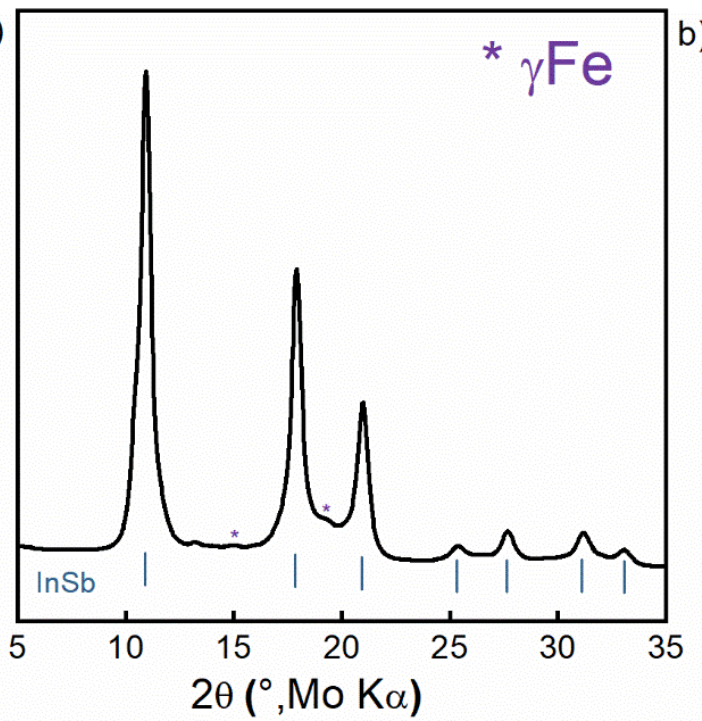

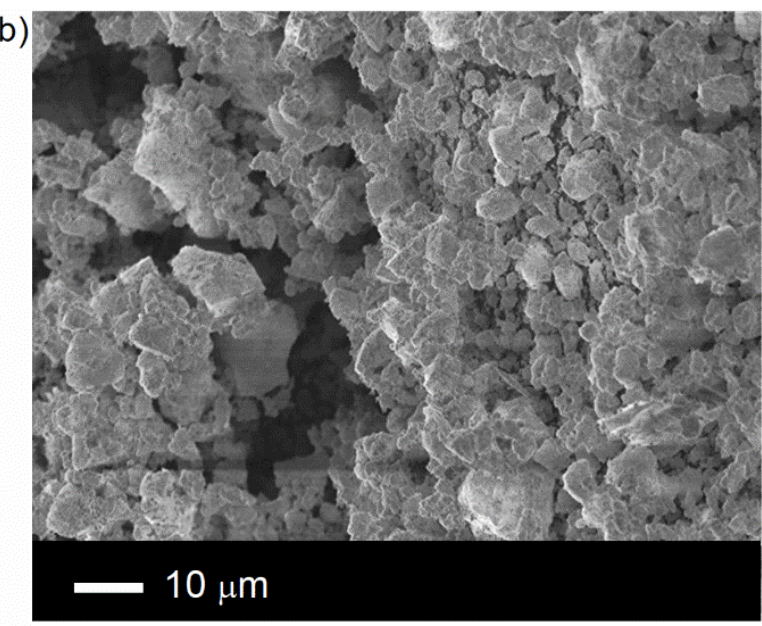

$10 \mu \mathrm{m}$

Figure 1. (a) XRD pattern and (b) SEM picture of the InSb powder obtained by high energy ballmilling (Bragg position of InSb as blue vertical bars).

\subsection{Electrochemical mechanism of InSb-Mg alloying: competition between crystallization and electrochemically-driven amorphization}

To determine if a beneficial coupling between In and Sb exists, the electrochemical properties of the InSb alloy were first compared with the behaviour of a simple mixture of pure micrometric In and $\mathrm{Sb}$ powders in stoichiometric amounts. The first magnesiation of the $\mathrm{In}+\mathrm{Sb}$ blend (Supplementary Information, Figure S2) presents only one electrochemical plateau at $\sim 0.09 \mathrm{~V} \mathrm{Mg}$ and only $0.6 \mathrm{Mg}^{2+}$ are inserted in the electrode. The voltage value of the plateau is characteristic of the reactivity of In with $\mathrm{Mg} .{ }^{20}$ Therefore, only In is reacting while $\mathrm{Sb}$ is completely inactive. 
This is expected as no electrochemical activity for $\mathrm{Sb}$ micrometric particles was observed previously with a fast decrease of potential down to $0 \mathrm{~V}_{\mathrm{Mg} .}{ }^{18,19}$ On the contrary, the $\mathrm{InSb}$ composite electrode (Figure 2a) is able to host 1.9 moles of $\mathrm{Mg}^{2+}$ in its structure, demonstrating a beneficial effect between the two elements. The electrochemical profile suggests that $\mathrm{Sb}$ is electrochemically activated by the presence of In. This behavior seems comparable to what was already showed by Murgia et al. ${ }^{18}$ for the $\mathrm{Bi}_{1-\mathrm{x}} \mathrm{Sb}_{\mathrm{x}}$ where antimony is activated in the presence of Bi for the first magnesiation, and will be discussed in more details below.

a)

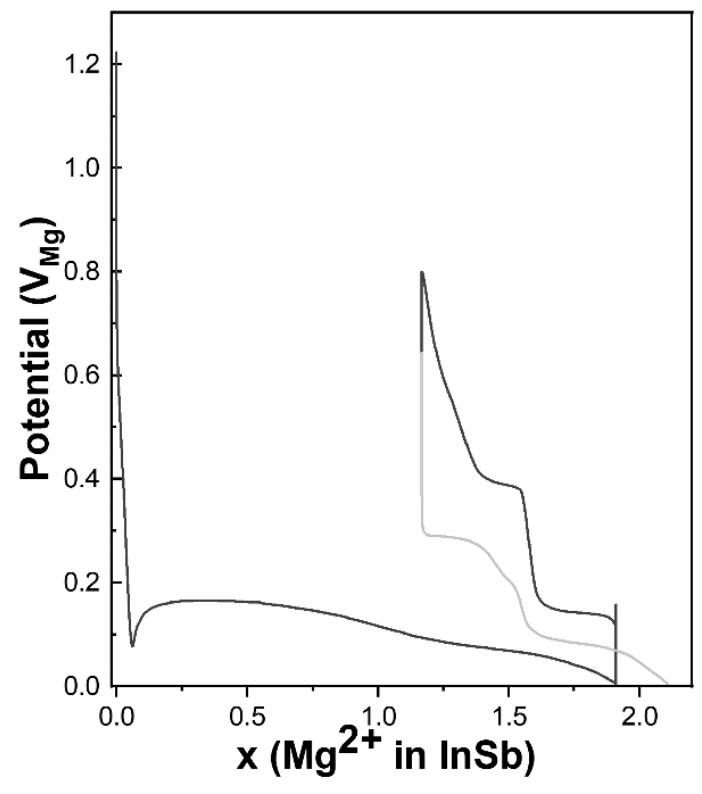

b)

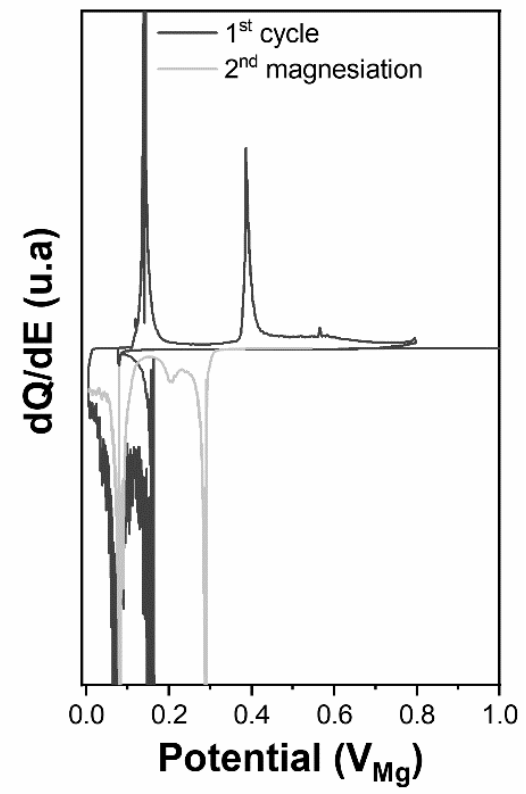

Figure 2. (a) Galvanostatic cycling of an $\mathrm{InSb} / \mathrm{Mg}$ battery at a $\mathrm{C} / 50$ rate and (b) corresponding incremental capacity profile.

The first 1.5 cycle of the $\mathrm{InSb} / \mathrm{Mg}$ battery at a constant rate of $\mathrm{C} / 50$ in galvanostatic mode (GCPL) and the corresponding incremental capacity (Figure 2a, b) shows a drastic change between the first and the second cycle. The first magnesiation exhibits two principal regions 
barely separated (Figure 2a). However, the presence of two electrochemical reactions appears more clearly on the representation of the incremental capacity (Figure $2 b$ ), where two peaks at approximatively $0.16 \mathrm{~V}_{\mathrm{Mg}}$ and $0.07 \mathrm{~V}_{\mathrm{Mg}}$ can be noted. As already reported in the literature, pure In electrodes display a flat plateau around $0.09 \mathrm{~V}_{\mathrm{Mg}}$ related to the two-phase reaction leading the formation of crystalline MgIn (Figure S3) ${ }^{20}$ For the Sb electrodes, the two-phase reaction with $\mathrm{Mg}$ is predicted at $0.31 \mathrm{~V}_{\mathrm{Mg}}$ to form $\mathrm{Mg}_{3} \mathrm{Sb}_{2}{ }^{18,19}$ Therefore, the alloying region around $0.16 \mathrm{~V}_{\mathrm{Mg}}$ (before $~ 1.25$ ), should be linked to the formation of $\mathrm{Mg}_{3} \mathrm{Sb}_{2}$. The second region occurring at a lower potential around $0.07 \mathrm{~V}_{\mathrm{Mg}}$ should be associated with the reaction of $\mathrm{In}$ with $\mathrm{Mg}$ to form MgIn. This agrees well with the electrochemical reactivity of the pure In and Sb elements, ${ }^{19,20}$ and can be summarized as follows:

$$
\operatorname{InSb}+2.5 \mathrm{Mg}^{2+}+5 e^{-} \rightarrow \frac{1}{2} M g_{3} S b_{2}+M g I n
$$

At the beginning of the first magnesiation, the cell voltage drops rapidly down to $\sim 0.07 \mathrm{~V}_{\mathrm{Mg}}$ (this value varies between $0.05-0.1 \mathrm{~V}_{\mathrm{Mg}}$ depending on the cell) but then rises again to finally reach the first alloying plateau at $0.16 \mathrm{~V}_{\mathrm{Mg}}$. As already seen in other materials $\mathrm{s}^{5,13,19,22,24}$ this can be related to the equilibrium between first the nucleation of the $\mathrm{Mg}_{3} \mathrm{Sb}_{2}$ grains and second the growth of the particles. The $\mathrm{Mg}-\mathrm{In} / \mathrm{Sb}$ electrochemical alloying potentials are not really stable in the first magnesiation but, at the end, the system reaches a capacity of $535 \mathrm{mAh} \mathrm{g}^{-1}$ which is very close to the theoretical capacity of $566 \mathrm{mAh} \mathrm{g}^{-1}$ (calculated based on the formation of $\mathrm{Mg}_{3} \mathrm{Sb}_{2}$ and MgIn).

The first demagnesiation (Figure 2a, b) shows two well-defined plateaus at $0.39 \mathrm{~V}_{\mathrm{Mg}}$ and 0.14 $\mathrm{V}_{\mathrm{Mg}}$. Considering the dealloying potential values of $\mathrm{Mg}_{3} \mathrm{Sb}_{2}{ }^{18,19}$ and $\mathrm{MgIn},{ }^{20,21}$ the higher plateau is attributed to the dealloying of $\mathrm{Mg}_{3} \mathrm{Sb}_{2}$, while the second is assigned to MgIn dealloying. $\mathrm{Mg}$ dealloying reaction occurs at 0.14 and $0.39 \mathrm{~V}_{\mathrm{Mg}}$ during charge so the system presents a 
consequential polarization of about $230 \mathrm{mV}$ (for the alloy $\mathrm{Mg}_{3} \mathrm{Sb}_{2}$ ) and $80 \mathrm{mV}$ (for $\mathrm{MgIn}$ ). The system is poorly reversible at the first cycle, with a capacity retention of only $39 \%$ (Figure 2a). Few factors can explain this low reversibility. The large volume expansion during the first cycle (theoretical volume expansion estimated $\sim 100 \%$ ) could lead to the disconnection of some active material particles from the global matrix, or $\mathrm{Mg}^{2+}$ diffusion can be impeded in some large particles due to the sluggish diffusion of $\mathrm{Mg}^{2+}$ in solids. ${ }^{5-9}$ A reactivity between the electrode and the electrolyte could also irreversibly consume electrons and/or $\mathrm{Mg}^{2+}$ ions, implying a poor stability of the alloy in the electrolyte, in contradiction to the expected stability of THF based solutions. ${ }^{35}$ Most probably, we believe that the irreversibility could arise from the poor ability of the $\mathrm{Mg}_{3} \mathrm{Sb}_{2}$ to be demagnesiated. ${ }^{18,19}$

In contrast with the first cycle, the second magnesiation (Figure 2a, b) exhibits two clear plateaus around 0.3 and $0.08 \mathrm{~V}_{\mathrm{Mg}}$ in agreement with the reactivity of $\mathrm{Sb}^{18,19}$ and $\mathrm{In}^{20}$ and a small third flexion in between at $0.21 \mathrm{~V}_{\mathrm{Mg}}$. The small third flexion may highlight a change in the electrochemical pathway, with for example a reorganization of the material structure upon alloying, or an electrochemical reactivity of some impurities in the powder. The presence of the higher plateau at $0.3 \mathrm{~V}_{\mathrm{Mg}}$ demonstrates that $\mathrm{Sb}$ is not only active at the first cycle but can partially be reversible upon cycling. This confirms the peculiar beneficial effect provided by the presence of In with $\mathrm{Sb}$. Strong morphology modification in the active material ${ }^{21}$ upon the first cycle could explain the large profile difference observed between the first and the second magnesiation. In fact, the electrochemical reaction can induce a complete disaggregation of the initial micrometric grains of active materials, inducing a grinding of the material explaining the different electrochemical behavior between the first and second cycle. ${ }^{21}$ 


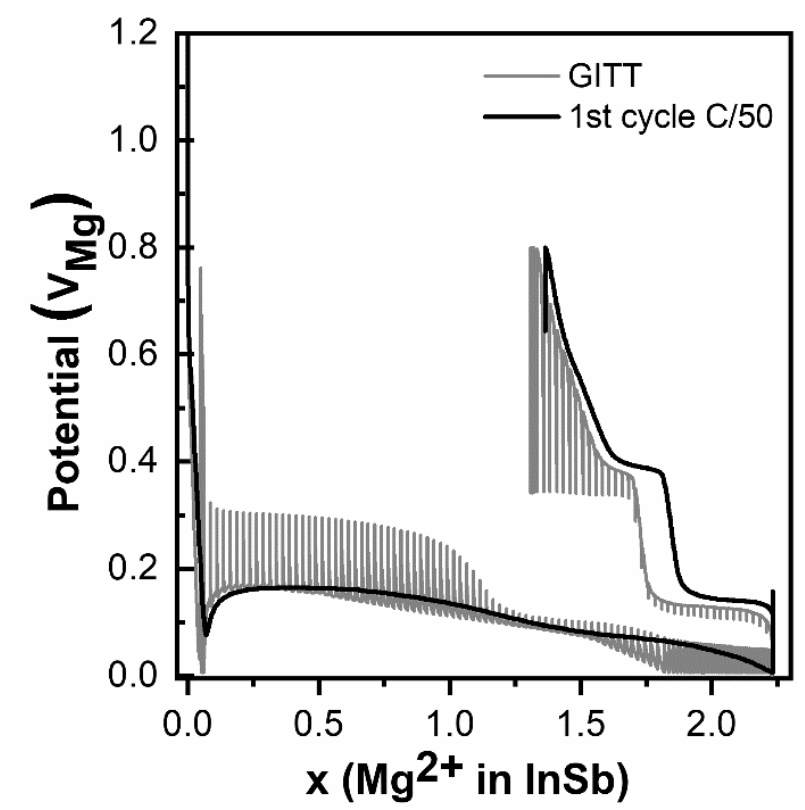

Figure 3. GITT profile (grey) at the first cycle obtained from an $\mathrm{InSb} / \mathrm{Mg}$ battery $(1 \mathrm{~h}$ of reduction/oxidation at a $\mathrm{C} / 50$ rate followed by 2 hours of relaxation) compared with the galvanostatic cycling at a $\mathrm{C} / 50$ rate (black).

In order to better understand the mechanism of $\mathrm{Mg}$ alloying/de-alloying in $\mathrm{InSb}$, a galvanostatic intermittent titration technique (GITT) was applied (Figure 3) and compared with the conventional galvanostatic cycling described previously (Figure 2a). The procedure allows the electrode to reach its equilibrium potential and can provide insights on the kinetics phenomena. Following the OCV points on the GITT, it is possible to see a different behavior upon alloying than the GCPL and a similar trend during the dealloying. In contrast to the conventional cycling, the thermodynamic potentials of alloying processes are clearly defined with two plateaus upon the magnesiation in GITT (Figure 3). The plateaus of the first magnesiation are observed around 0.3 and $0.06 \mathrm{~V}_{\mathrm{Mg}}$ compared to 0.16 and $0.07 \mathrm{~V}_{\mathrm{Mg}}$ for the GCPL. The successive formations of $\mathrm{Mg}_{3} \mathrm{Sb}_{2}$ and MgIn upon magnesiation of InSb are further confirmed. The polarization is reduced to $40 \mathrm{mV}$ for both $\mathrm{Mg}_{3} \mathrm{Sb}_{2}$ and $\mathrm{MgIn}$ compared to 230 
$\mathrm{mV}_{\mathrm{Mg}}$ and $80 \mathrm{mV}_{\mathrm{Mg}}$ in the conventional galvanostatic test respectively. The large difference observed between $\mathrm{CCV}$ and $\mathrm{OCV}$ value in the $\mathrm{Mg}_{3} \mathrm{Sb}_{2}$ formation region reveals a kinetic limitation at the first cycle, which will be discussed later on.

The conclusions drawn above on the formation of $\mathrm{Mg}_{3} \mathrm{Sb}_{2}$ and $\mathrm{MgIn}$ as products of the alloying reactions of InSb with $\mathrm{Mg}$ were confronted with ex situ XRD measurements on InSb composite electrodes cycled at $\mathrm{C} / 100$ rate. To follow the formation of the $\mathrm{Mg}$ alloys and to better understand the reaction mechanisms, cells were stopped and electrodes removed at different states of the magnesiation. The corresponding XRD patterns are presented on Figure 4 (complete patterns on Figure S4).

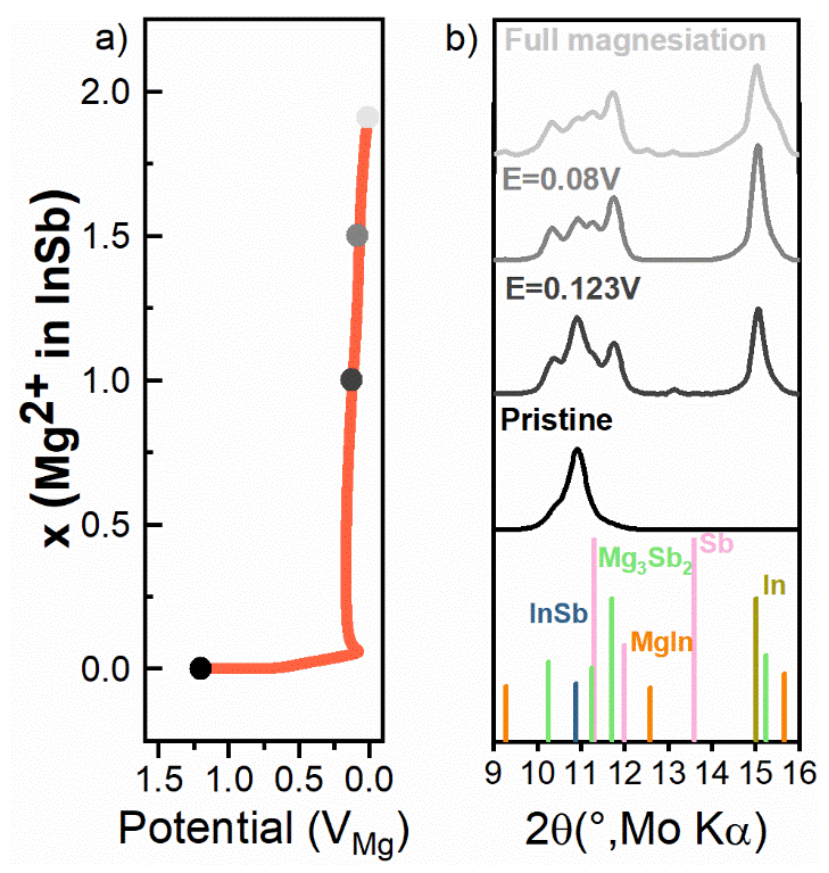

Figure 4. Ex situ XRD patterns collected on InSb-based composite electrodes stopped at different states of the magnesiation at a C/50 rate. The vertical bars show the Bragg position of InSb (blue), MgIn (orange), In (brown), $\mathrm{Sb}$ (pink) and $\mathrm{Mg}_{3} \mathrm{Sb}_{2}$ (green). 
The phase evolutions on the first magnesiation are discussed in the following points:

At the beginning of the magnesiation, up to the reaction of $\sim 1 \mathrm{Mg}^{2+}$, a large decrease of the InSb reflex and an increase of new reflexes at $10.3^{\circ}, 11.2^{\circ}$ and $11.7^{\circ}$ are observed. These new reflexes are characteristic of $\mathrm{Mg}_{3} \mathrm{Sb}_{2}{ }^{36}$ and therefore confirms the magnesiation of $\mathrm{Sb}$ to form $\mathrm{Mg}_{3} \mathrm{Sb}_{2}$, in agreement with the electrochemical data. Simultaneously another diffraction reflex corresponding to pure metallic indium ${ }^{37}$ appears at $15.0^{\circ}$, indicating that In is extruded from the InSb alloy, as already seen in the lithiation of $\mathrm{InSb}^{38}$

After the alloying of around $1.5 \mathrm{Mg}^{2+}$ within the material, $\mathrm{Mg}_{3} \mathrm{Sb}_{2}$ and pure In are still detected, while the intensity of the characteristic reflex of InSb at $10.9^{\circ}$ decreases.

After full magnesiation, $\mathrm{Mg}_{3} \mathrm{Sb}_{2}$ and pure In are still observed while some InSb remains, revealing that not all the active material has reacted. Surprisingly, while the electrochemical profile and ex situ diffraction data of In electrodes will suggest the formation of crystalline MgIn (Figure S3), only a small contribution of crystalline MgIn is supposedly detected with the small reflexes appearing at $9.3^{\circ}, 12.8^{\circ}$ and $15.6^{\circ}(\mathrm{P} 4 / \mathrm{mmm} \mathrm{MgIn})^{39}$. It is worth mentioning that the diffraction reflex of $\mathrm{Mg}_{3} \mathrm{Sb}_{2}$ at $15.2^{\circ}$ is close to the main reflex at $15.6^{\circ}$ of $\mathrm{MgIn}$, rendering the analysis of the patterns relatively complex. Above all, it is important to note that the characteristic reflexes of MgIn were not always observed on fully magnesiated samples when the tests were reproduced (Figure S5), suggesting the presence of MgIn in an amorphous state. 


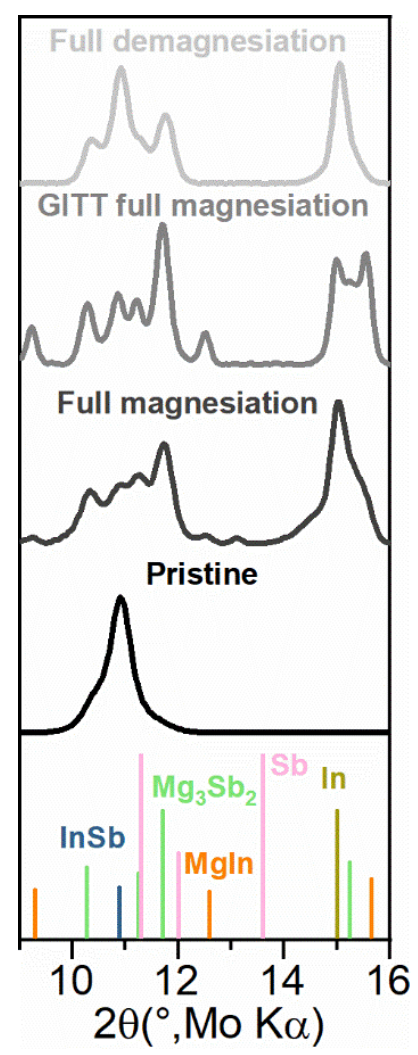

Figure 5. Ex situ XRD patterns collected on the pristine InSb powder, and on electrodes stopped at the end of the magnesiation at a $\mathrm{C} / 100$ rate either with a galvanostatic cycling or in GITT mode, and on an electrode cycled at a $\mathrm{C} / 100$ rate and stopped at the end of the first cycle (demagnesiation). The vertical bars show the Bragg position of InSb (blue), MgIn (orange), In (brown), $\mathrm{Sb}$ (pink) and $\mathrm{Mg}_{3} \mathrm{Sb}_{2}$ (green).

To better identify the phases present during $\mathrm{Mg}$ alloying in $\mathrm{InSb}$, XRD patterns from samples fully magnesiated either at a C/100 rate or in GITT mode were compared (Figure 5, complete patterns on Figure S6). The XRD pattern of the GITT sample collected at the end of the first magnesiation shows a different profile in comparison with the GCPL sample pattern. Interestingly the XRD pattern of the GITT magnesiated sample presents sharper and better- 
defined reflexes, denoting more highly-crystallized phases. More importantly, the main difference is the unambiguous presence of three sharp reflexes at $9.3^{\circ}, 12.8^{\circ}$ and $15.6^{\circ}$ which corresponds to the P4/mmm MgIn phase. MgIn crystallization is clearly evidenced on the GITT sample -in which the electrode is allowed to reach a steady state- while the crystallization is circumvented with the GCPL sample. The presence of amorphous MgIn seems counterintuitive as the magnesiation of pure $\operatorname{In}^{20}$ (Figure S3) and of an $\mathrm{InBi}$ alloy ${ }^{21}$ leads to crystalline MgIn. However the capacity extracted from InSb (Figure 2) can not only be justified by the alloying/dealloying process of $\mathrm{Sb}$. The relatively small proportion of crystalline $\mathrm{MgIn}$, if any, observed in the GCPL electrode, compared to what is expected from the electrochemical profile and capacity recovered, indirectly suggests an electrochemically-driven amorphization of the MgIn phase. The crystallization of MgIn is thus kinetically dependent, implying a struggle between amorphization and crystallization depending on the rate applied. What frustrates the crystallization of MgIn has still to be fully rationalized. However, we can suggest that the extrusion of In from InSb during the first part of the magnesiation could cause dramatic changes of morphology and/or enhance the atomic disorder and create nanosized domains of In (electrochemical grinding). The formation of highly reactive In nanoparticles could completely modify the reaction path of In with $\mathrm{Mg}$ and conducts to the formation of a nanosized amorphous MgIn phase. Moreover, the sluggish diffusion of $\mathrm{Mg}^{2+}$ could slow down the atomic rearrangement in the MgIn structure, while an inner strain could also hinder the formation of crystalline MgIn. ${ }^{29}$ In order to confirm our hypotheses, some in situ XRD and in situ X-ray absorption experiments should be performed to identify the phases formed at a more local scale.

By coupling the XRD characterization and electrochemical data, we thus propose the following reaction pathway for the first magnesiation of $\mathrm{InSb}$, based on two successive biphasic 
reactions governed by the magnesiation of $\mathrm{Sb}$ and $\mathrm{In}$, with first an extrusion of In and then an incomplete transformation of the InSb material which leads to the crystallization of $\mathrm{Mg}_{3} \mathrm{Sb}_{2}$ and the electrochemically-driven amorphization of MgIn using galvanostatic cycling:

$$
\begin{gathered}
\boldsymbol{I n S b}+\frac{3}{2} x \mathbf{M g}^{2+}+x e^{-} \rightarrow(1-x) \operatorname{InS} b+x\left(\frac{\mathbf{1}}{2} \boldsymbol{M} \boldsymbol{g}_{3} \boldsymbol{S} \boldsymbol{b}_{2}\right)+x \operatorname{In} \\
x \operatorname{In}+y e^{-}+y \mathbf{M g}^{2+} \rightarrow y \boldsymbol{M g I n}+(x-y) \operatorname{In}
\end{gathered}
$$

Finally, we also investigated the phases formed at the end of the first cycle. The XRD pattern acquired on a completely demagnesiated electrode is shown in Figure 5. Interestingly, the first demagnesiation does not produce $\mathrm{Sb}$ and $\mathrm{In}$ as pure elements from the demagnesiation of MgIn and $\mathrm{Mg}_{3} \mathrm{Sb}_{2}$ phases, but instead the intermetallic compound $\mathrm{InSb}$ is reformed as the major product. Nevertheless, some $\mathrm{Mg}_{3} \mathrm{Sb}_{2}$ and In still remain which demonstrates an uncompleted demagnesiation of the overall electrode and explain for the most part the large irreversibility observed in the first cycle.

\subsection{Cycling performance and evidence for Sb electrochemical activation}

The study of InSb-based composite electrodes was firstly proposed to investigate a possible synergy between In and $\mathrm{Sb}$. The alloy could present a better capacity due to the high capacity of the antimony, namely $660 \mathrm{mAh} \mathrm{g}^{-1},{ }^{18,19}$ and the lowest working potential of indium among the other p-block elements. ${ }^{20,21}$ It is interesting, from a fundamental point of view, to evaluate the electrochemical performance and to compare them with In and Sb-based electrodes already reported in the literature. ${ }^{18,20}$ 


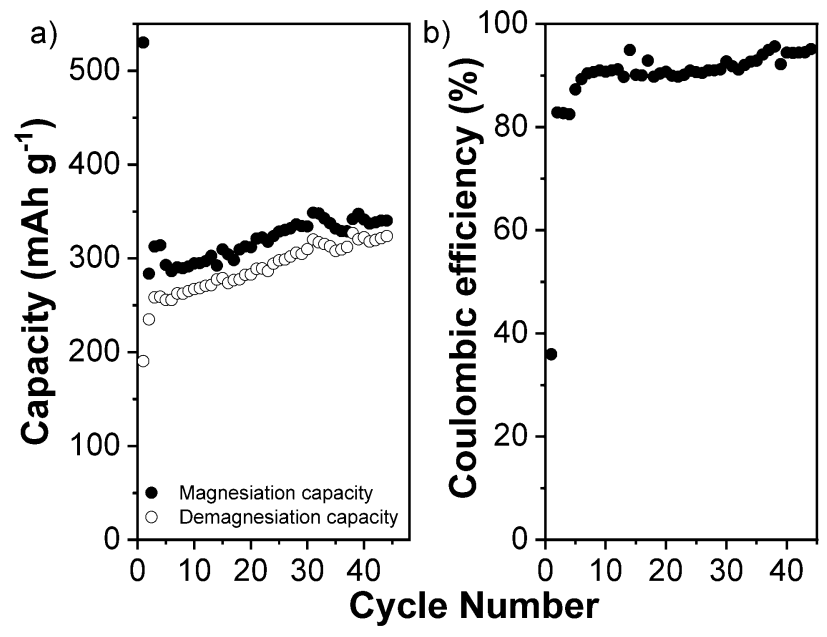

Figure 6. (a) Evolution of the capacity of magnesiation and demagnesiation of InSb/Mg battery at a C/50 rate during 50 cycles and (b) of the corresponding coulombic efficiency.

Electrochemical cycling tests at a $\mathrm{C} / 50$ rate were performed upon more than 40 cycles on an InSb-based electrode (Figure 6). Despite the lack of activity of the pure Sb reported previously, the InSb alloy presents capacities higher than indium composite electrodes (first magnesiation capacity around $460 \mathrm{mAh} \mathrm{g}^{-1}$ (theoretical capacity $\left.467 \mathrm{mAh} \mathrm{g}^{-1}\right)^{20}$ at least for the first cycle. After the first cycle a sharp decrease of the capacity is observed and then the capacity stabilizes for both alloying and dealloying reactions with a slight gradual increase from 270 to $350 \mathrm{mAh} \mathrm{g}^{-}$ 1. The capacity recovery upon cycling can be related to an in situ nanostructuration of the active material during cycling allowing a deeper diffusion of $\mathrm{Mg}^{2+}$ ions into the electrode and therefore generating a more important proportion of $\mathrm{InSb}$ being active towards $\mathrm{Mg}^{2+}$. However, electrolyte's degradation along cycling can also possibly explain the extra-capacity observed and give the impression of a global increase of the capacity. These capacities observed are nevertheless lower than those reached with pure In electrodes. Murgia et al. ${ }^{20}$ showed a first 
magnesiation capacity of $460 \mathrm{mAh} \mathrm{g}^{-1}$ with then capacities stabilizing approximatively around $440 \mathrm{mAh} \mathrm{g}^{-1}$. Nevertheless, we evidence for the first time a partial reversibility of $\mathrm{Sb}$ in an electrode for $\mathrm{Mg}$-ion batteries. The proportion of the magnesiation capacity due to $\mathrm{Mg}_{3} \mathrm{Sb}_{2}$ was calculated based on the capacity obtained on the first alloying plateau (Figure 7). The formation of $\mathrm{Mg}_{3} \mathrm{Sb}_{2}$ is responsible for $\sim 42 \%$ of the capacity at the first magnesiation while the value then slowly decreases to reach $\sim 20 \%$ after 20 cycles and $\sim 10 \%$ after 40 cycles. This confirms that $\mathrm{Sb}$ is electrochemically activated by the presence of In and that its contribution to the total capacity is not negligible. Despite a large irreversible capacity at the first cycle, we show that $\mathrm{InSb}$ cycling promotes the reactivity of $\mathrm{Sb}$, not only at the first magnesiation, but also upon further cycling. The activation of $\mathrm{Sb}$ in InSb could be explained by the formation of a peculiar interface favoring $\mathrm{Sb}$ reactivity. This has already been observed in the promotion of $\mathrm{Sn}$ reactivity in $\mathrm{SnSb}$ by the presence of $\mathrm{Sb}$, despite the inactivity of $\mathrm{Sb}$ in the material. ${ }^{11,12}$ Finally, we also suggest a possible effect of a different microstructure in the InSb material compared to a pure micrometric $\mathrm{Sb}$ powder. The different microstructure inside the active material could stimulate the reactivity of $\mathrm{Sb}$ and create a highly reactive $\mathrm{Mg}_{3} \mathrm{Sb}_{2}$ phase more prone to demagnesiation. These hypotheses need to be confirmed with further investigations. 


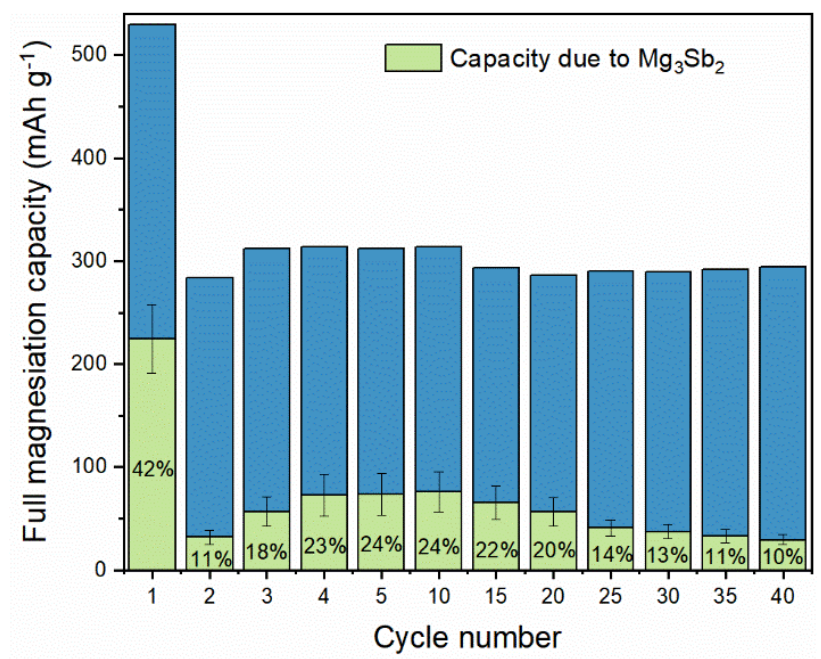

Figure 7. Evolution of the full capacity of magnesiation of $\mathrm{InSb} / \mathrm{Mg}$ battery and of the part of the capacity corresponding to the contribution of $\mathrm{Mg}_{3} \mathrm{Sb}_{2}$ (green) at a C/50 rate during 40 cycles.

The electrochemical performance of the micrometric InSb-based electrode was also evaluated through rate capability test from $\mathrm{C} / 50$ to $1 \mathrm{C}$ (Figure $\mathrm{S} 7$ ). It shows a steady decrease of the capacity with the increase of the current density. The capacity is maintained above $200 \mathrm{mAh} \mathrm{g}^{-1}$ until a $\mathrm{C} / 25$ rate while it then regularly decreases to reach almost no capacity at $1 \mathrm{C}$. These results manifest kinetics limitations during the InSb magnesiation/demagnesiation processes. This emphasizes the sluggish diffusion of $\mathrm{Mg}^{2+}$ in the solid and is probably accentuated by the reactivity of antimony ${ }^{18,19}$ in the alloy and the high stability of the ionic $\mathrm{Mg}-\mathrm{Sb}$ bonds ${ }^{40}$ in the $\mathrm{Mg}_{3} \mathrm{Sb}_{2}$ phase. However, we want to stress out that the present study was first aimed at understanding the fundamental electrochemical behavior of $\mathrm{InSb}$, thus formulations of the electrode and the electrolyte have not been optimized. We believe that nanostructuration of the material could improve this performance by reducing the diffusion paths for $\mathrm{Mg}^{2+}$ ions. 


\section{Conclusion}

The electrochemical reactivity and performance of the $\mathrm{InSb}$ alloy as a negative electrode for Mg-ion batteries have been investigated. As expected from the literature on pure In and $\mathrm{Sb}$, the potential profile of the first magnesiation evidences two successive two-phase reactions corresponding to the formation of $\mathrm{Mg}_{3} \mathrm{Sb}_{2}$ and MgIn. However, surprisingly, XRD patterns collected at different magnesiation states suggest a kinetically dependent electrochemicallydriven amorphization of MgIn. This phenomenon seems unique to the InSb phase as crystalline MgIn has always been detected in the literature in the case of pure In or InBi electrodes. This behavior suggests a possible competition between crystallization and amorphization in the material which could be explained by an increase of disorder at the atomic scale in the material, an internal strain or modification of the microstructure upon reaction. Further studies are required to understand the driving force the amorphization of MgIn, and how it can influence the electrochemical behavior and performance of $\mathrm{InSb}$, and in a broader context of alloy materials in metal batteries. Additionally, we also revealed a strong synergy between In and $\mathrm{Sb}$ in InSb, with the promotion of the electrochemical activity of $\mathrm{Sb}$ towards magnesiation. In contrast to what was already reported in other studies, $\mathrm{Sb}$ is shown for the first time to be able to partially react reversibly with $\mathrm{Mg}$ along few cycles. The first magnesiation reaches a capacity $>500 \mathrm{mAh} \mathrm{g}^{-1}$ and some subsequent capacities around $300 \mathrm{mAh} \mathrm{g}^{-1}$. Some questions remain on the mechanisms leading to the activation of $\mathrm{Sb}$ in the InSb alloy, whether it can involve a peculiar interface in the material or be related to the microstructure. This requires further investigation for example with in situ $\mathrm{XRD} / \mathrm{X}$-ray absorption to understand how to further trigger the full reactivity of $\mathrm{Sb}$ in $\mathrm{Mg}$ ion batteries. 


\section{Supporting Information}

Supplementary electrochemical data and ex situ X-Ray Diffraction data

\section{Conflicts of interest}

There are no conflicts to declare.

\section{Acknowledgment}

Financial funding from the Agence Nationale de la Recherche (ANR) of France under the contract ANR-16-CE05-0004 is acknowledged.

\section{References}

(1) Song, J.; Sahadeo, E.; Noked, M.; Lee, S. B. Mapping the Challenges of Magnesium Battery. J. Phys. Chem. Lett. 2016, 7, 1736-1749.

(2) Yoo, H. D.; Shterenberg, I.; Gofer, Y.; Gershinsky, G.; Pour, N.; Aurbach, D. Mg Rechargeable Batteries: An on-Going Challenge. Energy Environ. Sci. 2013, 6, 2265-2279.

(3) Muldoon, J.; Bucur, C. B.; Gregory, T. Quest for Nonaqueous Multivalent Secondary Batteries: Magnesium and Beyond, Chem. Rev., 2014, 114, 11683-11720.

(4) Bucur, C. B.; Gregory, T.; Oliver, A. G.; Muldoon, J. Confession of a Magnesium Battery, J. Phys. Chem. Lett., 2015, 6, 3578-3591.

(5) Shao, Y.; Gu, M.; Li, X.; Nie, Z.; Zuo, P.; Li, G.; Liu, T.; Xiao, J.; Cheng, Y.; Wang, C.;

et al. Highly Reversible Mg Insertion in Nanostructured Bi for Mg Ion Batteries. Nano Lett. 2014, 14, 255-260. 
(6) Aurbach, D.; Schechter, A.; Moshkovich, M.; Cohen, Y. On the Mechanisms of Reversible Magnesium Deposition Processes. J. Electrochem. Soc. 2001, 148, A1004-A1014.

(7) Mizrahi, O.; Amir, N.; Pollak, E.; Chusid, O.; Marks, V.; Gottlieb, H.; Larush, L.; Zinigrad, E.; Aurbach, D. Electrolyte Solutions with a Wide Electrochemical Window for Rechargeable Magnesium Batteries. J. Electrochem. Soc. 2008, 155, A103-A109.

(8) Aurbach, D.; Gizbar, H.; Schechter, A.; Chusid, O.; Gottlieb, H. E.; Gofer, Y.; Goldberg, I. Electrolyte Solutions for Rechargeable Magnesium Batteries Based on Organomagnesium Chloroaluminate Complexes. J. Electrochem. Soc. 2002, 149, A115-A121.

(9) Mohtadi, R.; Mizuno, F. Magnesium Batteries: Current State of the Art, Issues and Future Perspectives. Beilstein J. Nanotechnol. 2014, 5, 1291-1311.

(10) Aurbach, D.; Lu, Z.; Schechter, A.; Gofer, Y.; Gizbar, H.; Turgeman, R.; Cohen, Y.; Moshkovich, M.; Levi, E. Prototype Systems for Rechargeable Magnesium Batteries. Nature 2000, 407, 724 .

(11) Parent, L. R.; Cheng, Y.; Sushko, P. V.; Shao, Y.; Liu, J.; Wang, C.-M.; Browning, N. D. Realizing the Full Potential of Insertion Anodes for Mg-Ion Batteries Through the Nanostructuring of Sn. Nano Lett. 2015, 15, 1177-1182.

(12) Cheng, Y.; Shao, Y.; Parent, L. R.; Sushko, M. L.; Li, G.; Sushko, P. V.; Browning, N. D.; Wang, C.; Liu, J. Interface Promoted Reversible Mg Insertion in Nanostructured TinAntimony Alloys. Adv. Mater. 2015, 27, 6598-6605.

(13) Singh, N.; Arthur, T. S.; Ling, C.; Matsui, M.; Mizuno, F. A High Energy-Density Tin Anode for Rechargeable Magnesium-Ion Batteries. Chem. Commun. 2012, 49, 149-151. 
(14) Singh, N.; Matsui, M. Bismuth-Tin Binary Anodes for Rechargeable Magnesium-Ion Batteries, US Patent 8647770 B2, February 11, 2014.

(15) Kitada, A.; Kang, Y.; Uchimoto, Y.; Murase, K. Electrochemical Reactivity of Magnesium Ions with Sn-Based Binary Alloys (Cu-Sn, Pb-Sn, and In-Sn). ECS Trans. 2014, 58, $75-80$.

(16) Yaghoobnejad Asl, H.; Fu, J.; Kumar, H.; Welborn, S. S.; Shenoy, V. B.; Detsi, E. In Situ Dealloying of Bulk $\mathrm{Mg}_{2} \mathrm{Sn}$ in Mg-Ion Half Cell as an Effective Route to Nanostructured Sn for High Performance Mg-Ion Battery Anodes. Chem. Mater. 2018, 30, 1815-1824.

(17) Singh, N.; Matsui, M. Indium-Tin Binary Anodes for Rechargeable Magnesium-Ion Batteries, US Patent 8673493 B2, March 18, 2014.

(18) Murgia, F.; Laurencin, D.; Weldekidan, E. T.; Stievano, L.; Monconduit, L.; Doublet, M.-L.; Berthelot, R. Electrochemical Mg Alloying Properties along the $\mathrm{Sb}_{1-\mathrm{x}} \mathrm{Bi}_{\mathrm{x}}$ Solid Solution. Electrochim. Acta 2018, 259, 276-283.

(19) Arthur, T. S.; Singh, N.; Matsui, M. Electrodeposited Bi, Sb and $\mathrm{Bi}_{1-\mathrm{x}} \mathrm{Sb}_{\mathrm{x}}$ Alloys as Anodes for Mg-Ion Batteries. Electrochem. Commun. 2012, 16, 103-106.

(20) Murgia, F.; Weldekidan, E. T.; Stievano, L.; Monconduit, L.; Berthelot, R. First Investigation of Indium-Based Electrode in Mg Battery. Electrochem. Commun. 2015, 60, 5659.

(21) Murgia, F.; Monconduit, L.; Stievano, L.; Berthelot, R. Electrochemical Magnesiation of the Intermetallic InBi through Conversion-Alloying Mechanism. Electrochim. Acta 2016, 209, $730-736$. 
(22) Periyapperuma, K.; Tran, T. T.; Purcell, M. I.; Obrovac, M. N. The Reversible Magnesiation of Pb. Electrochim. Acta 2015, 165, 162-165.

(23) Ramanathan, M.; Benmayza, A.; Prakash, J.; Singh, N.; Mizuno, F. A Porous Electrode Model for the Magnesiation and Demagnesiation of a Bismuth Electrode in Rechargeable Magnesium-Ion Cells. J. Electrochem. Soc. 2016, 163, A477-A487.

(24) DiLeo, R. A.; Zhang, Q.; Marschilok, A. C.; Takeuchi, K. J.; Takeuchi, E. S. Composite Anodes for Secondary Magnesium Ion Batteries Prepared via Electrodeposition of Nanostructured Bismuth on Carbon Nanotube Substrates. ECS Electrochem. Lett. 2015, 4, A10A14.

(25) Wang, W.; Liu, L.; Wang, P.-F.; Zuo, T.-T.; Yin, Y.-X.; Wu, N.; Zhou, J.-M.; Wei, Y.; Guo, Y.-G. A Novel Bismuth-Based Anode Material with a Stable Alloying Process by the Space Confinement of an in Situ Conversion Reaction for a Rechargeable Magnesium Ion Battery. Chem. Commun. 2018, 54, 1714-1717.

(26) Murgia, F.; Stievano, L.; Monconduit, L.; Berthelot, R. Insight into the Electrochemical Behavior of Micrometric $\mathrm{Bi}$ and $\mathrm{Mg}_{3} \mathrm{Bi}_{2}$ as High Performance Negative Electrodes for $\mathrm{Mg}$ Batteries. J. Mater. Chem. A 2015, 3, 16478-16485.

(27) Zhang, Q.; Takeuchi, E. S.; Takeuchi, K. J.; Marschilok, A. C. High Energy Density Electrode Materials for Rechargeable Magnesium Batteries. ECS Trans. 2015, 66, 171-181.

(28) Limthongkul, P.; Jang, Y.-I.; Dudney, N. J.; Chiang, Y.-M. Electrochemically-Driven Solid-State Amorphization in Lithium-Silicon Alloys and Implications for Lithium Storage. Acta Mater. 2003, 51, 1103-1113. 
(29) Baggetto, L.; Hah, H.-Y.; Jumas, J.-C.; Johnson, C. E.; Johnson, J. A.; Keum, J. K.; Bridges, C. A.; Veith, G. M. The Reaction Mechanism of SnSb and Sb Thin Film Anodes for Na-Ion Batteries Studied by X-Ray Diffraction, ${ }^{119} \mathrm{Sn}$ and ${ }^{121} \mathrm{Sb}$ Mössbauer Spectroscopies. $J$. Power Sources 2014, 267, 329-336.

(30) Suryanarayana, C. Mechanical Alloying and Milling. Prog. Mater. Sci. 2001, 46, 1-184.

(31) Fecht, H. J.; Hellstern, E.; Fu, Z.; Johnson, W. L. Nanocrystalline Metals Prepared by High-Energy Ball Milling. Metall. Trans. A 1990, 21, 2333.

(32) Matsui, M.; Arthur, T. S. Active Material for Rechargeable Battery, US Patent 8685564 B2, April 1, 2014.

(33) Johnson, C. S.; Vaughey, J. T.; Thackeray, M. M.; Sarakonsri, T.; Hackney, S. A.; Fransson, L.; Edström, K.; Thomas, J. O. Electrochemistry and In-Situ X-Ray Diffraction of InSb in Lithium Batteries. Electrochem. Commun. 2000, 2, 595-600.

(34) Ersching, K.; Campos, C. E. M.; de Lima, J. C.; Grandi, T. A. Structural and Thermal Studies of Mechanical Alloyed InSb Nanocrystals. Mater. Chem. Phys. 2008, 112, 745-748.

(35) Lu, Z.; Schechter, A.; Moshkovich, M.; Aurbach, D. On the Electrochemical Behavior of Magnesium Electrodes in Polar Aprotic Electrolyte Solutions. J. Electroanal. Chem. 1999, 466, 203-217.

(36) Martinez-Ripoll, M.; Haase, A.; Brauer, G. The Crystal Structure of $\alpha-\mathrm{Mg}_{3} \mathrm{Sb}_{2}$. Acta Crystallogr. B 1974, 30, 2006-2009. 
(37) Wołcyrz, M.; Kubiak, R.; Maciejewski, S. X-ray investigation of thermal expansion and atomic thermal vibrations of tin, indium, and their alloys. Phys. Status Solidi B 1981, 107, 245253.

(38) Vaughey, J. .; Johnson, C.; Kropf, A.; Benedek, R.; Thackeray, M.; Tostmann, H.; Sarakonsri, T.; Hackney, S. A.; Fransson, L.; Edström, K.; et al. Structural and Mechanistic Features of Intermetallic Materials for Lithium Batteries. J. Power Sources 2001, 97-98, 194197.

(39) Ino, N.; Hirabayashi, M.; Ogawa, S. X-Ray and Thermal Analyses of the Order-Disorder Transition in Magnesium-Indium Alloys. Trans. Jpn. Inst. Met. 1965, 6, 172-178.

(40) Watson, L. M.; Marshall, C. A. W.; Cardoso, C. P. On the Electronic Structure of the Semiconducting Compounds $\mathrm{Mg}_{3} \mathrm{Bi}_{2}$ and $\mathrm{Mg}_{3} \mathrm{Sb}_{2}$. J. Phys. F Met. Phys. 1984, 14, 113. 


\section{TOC Graphic}

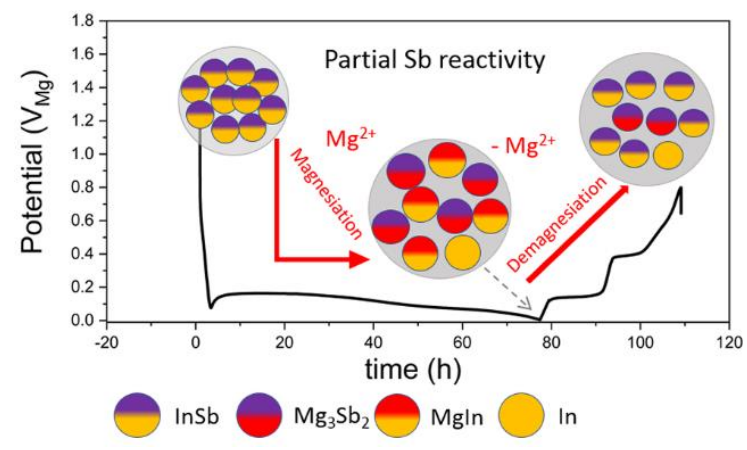

